Revista de Antropología Social

ISSN: 1131-558X

http://dx.doi.org/10.5209/RASO.57154

\title{
Miradas cómplices: antropología y empresa
}

López, Sergio D. 2017. Antropología de la empresa. Barcelona: Ediciones Bellaterra.

Acaba de ver la luz una obra, llamada a ejercer una gran influencia entre los cultivadores de la antropología, con el título de Antropología de la empresa, alusivo este último a una especialidad de la antropología en la que los antropólogos españoles no se han prodigado. El hecho no deja de ser extraño, si se toma en consideración la idea de que la empresa constituye una especie de microcosmos, en cuyo seno tienen lugar relaciones sociales, unas veces entre iguales y otras de carácter jerárquico que devienen en subordinación y en dominancia; pero la empresa es también el marco de la existencia de grupos cooperativos, todo lo cual la convierte en una especie de sociedad a escala reducida. La empresa es una estructura muy sensible a los procesos de cambio, que, cuando se producen, se acompañan de tensiones en el ámbito de los valores, que afectan a todos y cada uno de los miembros que la componen, y donde se manifiesta la conflictividad con harta frecuencia. La tensión se explica porque, a menudo, las expectativas de unos no coinciden con las de los otros, y no sólo por lo que se refiere a las posibles posiciones antagónicas entre el empresario y los trabajadores, sino también debido a los enfrentamientos que se producen, incluso entre iguales, por razón de intereses, o de edad y de género, por ejemplo. En consecuencia, la empresa es un nudo social que no puede sino despertar el mayor interés de los antropólogos, $\mathrm{y}$, sin embargo, los antropólogos españoles han mostrado hasta el presente una escasa atención hacia el tema, aunque los resultados, siendo cuantitativamente modestos, son meritorios desde cualquier punto de vista.

El propio autor del libro nos recuerda que los precedentes españoles de su trabajo se hallan, en primer lugar, en la obra de C. Esteva (1973) Antropología industrial, verdadero punto de partida de un itinerario que, ciertamente, no ha sido todo lo feliz que se prometía, si se tiene en cuenta que hubo de esperarse hasta finales de siglo para que R. Cuesta Ávila (1998) publicara su monografía, producto de una tesis doctoral, sobre la factoría Suzuki de Jaén, justamente al tiempo que Jordi Roca (1998) entrega a la imprenta su novedoso texto sobre Antropología industrial y de la empresa. Y aún habrían de pasar unos pocos años más antes de que, ya en el nuevo siglo, Carlos Bezos Daleske (2003) culminara su tesis doctoral sobre el centro de funciones compartidas de Daimler Chrysler, muy poco tiempo antes de que A. Aguirre (2004) diera a la imprenta su libro sobre Antropología de las organizaciones, en el que este autor se acerca al mundo empresarial. En el medio, el antropólogo norteamericano Davydd Greenwood (1989), juntamente con José Luís González Santos, había dado a conocer su trabajo sobre las cooperativas de Mondragón. Éste es el esbozo de un breve recorrido que, ahora, corriendo el tiempo, alcanza un nuevo y elevado hito con la edición de la obra de 
Sergio D. López, la cual nos ofrece una visión muy rigurosa y avanzada de ese ámbito de la antropología social que es el mundo de la empresa.

Como inmediatamente se deduce, estamos ante un libro de madurez, propio de un antropólogo curtido, en posesión de una sólida formación, que ha velado armas en distintas universidades norteamericanas y que ha dado vida a uno de los proyectos más fascinantes de la antropología española o, como él preferiría decir, a buen seguro, de la antropología iberoamericana ${ }^{1}$. Formado en el ámbito de las Ciencias Económicas y Empresariales, en las que obtuvo su Licenciatura, Sergio D. López realizó una loable tesis doctoral (Violencia y liderazgo: un modelo interpretativo del poder social a partir de cuatro escenarios etnográficos) en el Departamento de Antropología Social de la Universidad Complutense de Madrid en 2008, por la que obtuvo el Premio Extraordinario de Doctorado. Es posible que el hecho de haber desarrollado su carrera profesional como economista, antes de dedicarse a la antropología, le haya predispuesto para acometer la elaboración de una Antropología de la empresa, sin que ello haya supuesto el abandono de otras investigaciones de antropología aplicada, como la que viene desarrollando desde hace algunos años entre los mayas choles de Chiapas, en México.

La Antropología de la empresa que nos ofrece este profesor de The State University of New York at Potsdam, que ha investigado e impartido durante años docencia, entre otras universidades, en la University of Virginia y en la Southern Methodist University de Texas, es una antropología que, teniendo un fuerte componente teórico y académico es, asimismo, una antropología aplicada o práctica, como, en general, lo es la antropología de la empresa, que trasciende el ámbito de la antropología económica para desbordarse sobre la totalidad de la antropología social y desparramarse sobre el resto de las ciencias sociales. De hecho, la empresa, lejos de las connotaciones con las cuales es presentada por quienes la desconocen, es una unidad económico-social que constituye el resultado de una conjunción de medios personales, materiales e inmateriales, que, debidamente imbricados, hacen posible la producción de bienes, de servicios, o de ambos, con destino al mercado, contando con la atribución a un empresario que, gracias a su capacidad jurídica, puede participar en el tráfico económico, como titular de derechos y como titular de obligaciones.

La obra de Sergio D. López supone un notable avance para los estudios antropológicos por muchas razones. Se vale de una metodología comparativa, bien conocida por los antropólogos, que le permite analizar una gran cantidad de casos con un singular rigor, recurriendo para ello a la distinción de C. Geertz (1973) entre modelos de y modelos para, esto es, a la diferencia entre modelos que podemos llamar "naturales" y modelos que podemos llamar "construidos". Unos y otros son esquemas culturales, pero, mientras que los primeros muestran pautas socialmente instituidas, los segundos tienen una finalidad práctica que posee un gran interés para la antropología de la empresa. Una cosa son los estudios etnográficos que nos muestran los hábitos de consumo de una sociedad, y otra son los estudios etnográficos de hábitos de consumo con el objeto de mejorar un producto (López, 2017: 15-17). Ciertamente que los modelos de se convierten en modelos

Sergio D. López es creador, editor y director de la prestigiosa AIBR, Revista de Antropología Iberoamericana, probablemente la publicación periódica de antropología con mayor difusión en el mundo hispánico. 
para con cierta espontaneidad, puesto que la mera descripción de un aspecto de la cultura puede generar cambios en la propia cultura.

El libro, concebido como una obra de antropología aplicada, contiene alrededor de medio centenar de casos, detalladamente examinados, gracias a los cuales se puede seguir el efecto de los conocimientos teóricos de la antropología aplicados a la empresa en los últimos ochenta años, no sólo por antropólogos sino también por otros científicos sociales. La dilatada serie de casos rastreados comienza con el célebre estudio de la factoría Hawthorne, de la empresa Western Electric, analizado cuidadosamente en 1930 por dos conocidos profesores de la Universidad de Harvard, el psiquiatra Elton Mayo y el antropólogo Lloyd Warner (López, 2017: 40-47). El caso es del máximo interés porque la mirada que tienden los autores está encuadrada por la llamada Escuela de Relaciones Humanas, y constituiría el primero de los grandes proyectos de organización empresarial sustentado en técnicas etnográficas, cuya mayor virtud consistiría en poner el foco en las dinámicas sociales que recaen sobre el proceso productivo, lejos de la contemplación del ser humano como una pieza más de la maquinaria empresarial, tal y como pretendía la Organización Científica del Trabajo (OCT), cimentada sobre los principios del taylorismo, los cuales, por cierto, siguen dirigiendo actualmente, en buena medida, los procesos de producción, de comercialización y de administración empresarial.

La larga nómina de ejemplos que recorren el libro concluye con un grupo de casos que tratan de conferir aplicación a la teoría de Mauss (1923) sobre el don. Las cosas que damos a los demás son parte de nosotros mismos, de suerte que experimentan el retorno por vía de la reciprocidad. En antropología de la empresa, los bienes que nos asisten en nuestra cotidianidad son algo más que la expresión de nuestros gustos: son extensiones de nuestra propia identidad, de nuestros valores y de nuestras sensaciones. De este modo, la antropología teórica acabaría convirtiéndose en el epicentro del proyecto realizado para Cadillac en la primera década del siglo actual por parte de T. de Waal Malefyt y R. Morais, mediante el cual se trataba de romper la asociación de la marca con los ricos y ancianos propietarios de sus vehículos, rebajando para ello en varias décadas la edad media de estos propietarios, pero sin renunciar a privilegiar la marca Cadillac como un valor de lujo (López, 2017: 116-118). Lo primero que hicieron los autores del proyecto fue un estudio etnográfico, en el sur de California, acerca de los potenciales compradores que estaban entre los treinta y los cuarenta y nueve años, tratando de ligar la marca con la imagen de este activo segmento de edad, caracterizado por una seductora estética, unos atractivos gustos, un estilo diferente y unos nuevos valores, y servirse del efecto de una campaña publicitaria, atrevida y rompedora, que se desarrolló entre 2002 y 2006, en la que se aprovechaban los momentos más envolventes de la cultura norteamericana, coincidiendo con el Super Bowl y con otros eventos deportivos, como el Open de Tenis de los Estados Unidos.

Posteriormente, el autor de la Antropología de la empresa se detendrá en demostrar cómo no sólo las cosas son extensiones de las personas, sino que las personas también son extensiones de las cosas, según trató de probar B. Latour (1991) por vía de lo que él denominó principio de simetría generalizada. Significa esto que, si bien el automóvil puede ser una extensión de nuestra personalidad, no es menos cierto que la marca de nuestro automóvil encuentra en los usuarios su propia extensión, de modo que, casi sin quererlo, nos convertimos en la imagen 
de las marcas registradas de los objetos que utilizamos en nuestra vida diaria, o en la de los establecimientos que frecuentamos. Sergio D. López (2017: 119) nos lo enseña con uno de los proyectos que cierran la imponente relación de ejemplos empleados, que en esta ocasión es el de Lucy Kimbell y su estudio etnográfico aplicado al diseño de sistemas de salud en servicios para la tercera edad del Reino Unido.

¿Dónde reside el enorme acierto del autor a la hora de manejar su dilatado repertorio de casos? Creo que en haber sabido reducir cada caso a un momento del proceso, lo cual le ha permitido no sólo gestionar un enorme volumen de información sino, complementariamente, lograr que el lector focalice con precisión lo sustancial del caso. Es evidente que la experiencia de nuestro antropólogo como director financiero y como consultor ha coadyuvado al logro del mejor resultado. $\mathrm{El}$ autor de la obra parte de que la empresa se compone de tres grandes sectores o pilares, profundamente imbricados entre sí, pero, al mismo tiempo, dotados de un cierto grado de autonomía. El siguiente paso, por tanto, consistió en segregar, hasta donde era posible, los procesos que alimentan cada uno de estos sectores. Así, cuando se refiere al primero de los pilares, al de la producción, procede a desdoblar la misma en dos subprocesos, el de producción propiamente dicho y el de diseño. El segundo de los pilares, el denominado comercial, lo fragmenta en tres subprocesos: la publicidad, el consumo y la atención al cliente. Y el tercero de los pilares, el de la administración, lo subdivide en recursos humanos y en contabilidad.

El autor, a propósito, nos recordará dos cosas; la primera es que los proyectos de la empresa son los menos en comparación con los proyectos para la empresa, mientras que la segunda es que la antropología de la empresa destaca claramente en el ámbito de la comercialización de los bienes y servicios, y especialmente en todo lo relativo al consumo, si bien algunos aspectos de la producción han resultado del máximo interés para la antropología de la empresa, como es el del diseño. De ello se sigue que el aspecto menos atractivo para la antropología de la empresa, hasta el presente, ha sido el administrativo, aunque la obra nos descubre el interés de muchos investigadores por esa parte sensible de la empresa que es la de los recursos humanos, por más que éstos sean parte del pilar administrativo (López, 2017: 15-17). Así se evidencia en el caso de la referida investigación de Mayo y Warner sobre la Hawthorne, o en el de Cuesta Ávila sobre Suzuki Santana, o en el de Altimare sobre la General Motors, e incluso en el del propio Sergio D. López sobre la multinacional Re/Max en España, aparte del referido caso de Kimbell y el proyecto de atención a la tercera edad en el Reino Unido.

Verdaderamente, estamos ante una obra que alcanza niveles de excelencia a lo largo de sus páginas, por lo que no es excesivo decir que se convertirá en un texto muy socorrido por todos cuantos nos dedicamos a la docencia y a la investigación de la antropología. Es obligado decir que la Antropología de la empresa nos proporciona valiosos conocimientos teóricos, pero también metodológicos. Todos sabemos que uno de los grandes problemas de la observación etnográfica reside en que el informante no se comporta de la misma manera en su vida ordinaria que cuando se halla ante el observador y se sabe observado, lo cual convierte al primero de éstos en víctima de una paradoja, a la que se denomina, precisamente, con el nombre de paradoja del observador (López, 2017: 51, 173). Este hecho queda soberbiamente ilustrado con el caso Hawthorne, cuando se evidencia que las empleadas no producen más por disponer de mejor luz sino por sentirse observadas. 
Sergio D. López (2017: 51) nos traslada cuidadosamente a distintos escenarios, a fin de que podamos comprender mejor esta paradoja. Así, nos sitúa ante la fascinante observación de W. Labov. Aunque es evidente que los registros fonéticos de la persona cambian, por ejemplo, con la clase social, o con el nivel de instrucción, o con el género, quizá no reparamos lo suficiente en que hay personas que modifican sus registros fonéticos de una manera sorprendente por motivos profesionales, como sucede con los vendedores que tratan de maximizar sus transacciones hablando de la misma manera que lo hacen sus múltiples clientes. Sin embargo, quizá no hemos considerado lo suficiente que esto mismo les sucede a nuestros propios informantes, que no sólo modifican la conducta y las actitudes cuando hablan con nosotros, sino que también realizan selecciones alteradas de sus recuerdos, e introducen modificaciones en la sintaxis, en el léxico y en la fonética, de modo que nosotros percibimos una realidad distorsionada, de la que ni siquiera escapa, frecuentemente, la observación participante. Sabedor de la circunstancia, Labov perfeccionó su metodología, basada en lo que Lucy Suchman denomina acciones situadas, en alusión a la recogida de datos por parte del investigador mientras los informantes realizan sus actividades más diversas, especialmente cuando estos últimos pierden la sensación de estar siendo observados.

Sergio D. López es el guía amable que nos acompaña en el libro por los vericuetos de la etnografía, por ejemplo, introduciéndonos en la importancia del análisis de redes y relaciones sociales, y lo hace mediante una auténtica lección de metodología y de técnicas etnográficas. Tomando como antecedente lejano el trabajo de John Barnes en un poblado de pescadores noruego, el autor de Antropología de la empresa nos propone diferentes investigaciones realizadas en el ámbito empresarial, con metodología antropológica, que resultan cruciales para entender el papel de los nodos de conexión entre individuos y entre grupos. Una de estas investigaciones es la que dio vida al proyecto que desarrolló un grupo de antropólogos de la Universidad de Northern Arizona la década pasada, en la General Motors, con el título de Ideal Cultural Model, y que les permitió descubrir empleados que resultaban claves, determinantes o imprescindibles para la organización (López, 2017: 66), aun sin formar parte del organigrama oficial, debido a su singular capacidad para tender puentes y establecer comunicaciones en el seno del colectivo.

En fin, Sergio D. López es también el amigo cortés que nos traslada a las dependencias empresariales de los conceptos, y nos enseña a distinguir entre cultura de la empresa y cultura organizacional de la empresa (López, 2017: 85-86). La primera, nos dirá, se parapeta en pautas finamente atadas por el tiempo, como la costumbre de los operarios de acudir a un pub cercano al terminar la jornada el último día de la semana, mientras que la segunda obedece a un diseño racional que incluye el predominio de un color en la vestimenta, la reunión de los directivos del lunes por la mañana, o el encuentro de los jefes de sección de los jueves por la tarde en torno al café. Después de lo dicho hasta aquí, no es excesivo añadir que nos encontramos ante una obra de consulta obligada por parte de profesores y alumnos, seguramente llamada a integrar las bibliografías académicas y a convertirse en el liber amicorum de muchos investigadores de las ciencias sociales.

Eloy Gómez Pellón

Universidad de Cantabria gomezel@unican.es 


\section{Bibliografía}

Aguirre Baztán, A. (2004). La cultura de las organizaciones. Barcelona: Ariel.

Bezos Daleske, C. (2004). Producción de valor y cambio social en el capitalismo flexible. Madrid: Universidad Autónoma.

Cuesta Ávila, R. (1998). Japón en Jaén: intersección de identidades en un centro de producción. Madrid: Universidad Complutense.

Esteva Fabregat, C. (1973). Antropología industrial. Barcelona: Planeta.

Geertz, C. (1992) [1973]. La interpretación de las culturas. Barcelona: Gedisa.

Greenwood, D. J. y González Santos, J. L. (1989). Culturas de Fagor: Estudio antropológico de las cooperativas de Mondragón. San Sebastián: Txertoa.

Labov, W (1972). "The Social Stratification of (R) in New York City Departament Stores", en Labov, Sociolinguistic Patterns. Filadelfia: University of Pennsylvania Press.

Latour, B. (2007) [1991]. Nunca fuimos modernos. Ensayo de antropología simétrica. Buenos Aires: Siglo XXI.

López, Sergio D. (2017). Antropología de la empresa. Barcelona: Edicions Bellaterra.

Mauss, M. (1997) [1923]. "Essai sur le don. Forme et raison de l'echange dans les sociétés archaïques”, en Mauss, M., Sociologie et Anthropologie. París: PUF, pgs. 149-279.

Roca y Girona, J. (1998). Antropología industrial y de la empresa. Barcelona: Ariel.

Waal Malefyt, T. de y Moraes, R. J. (2013). Advertising and Anthropology: Ethnographic Practice and Cultural Perspectives. Oxford: Berg. 